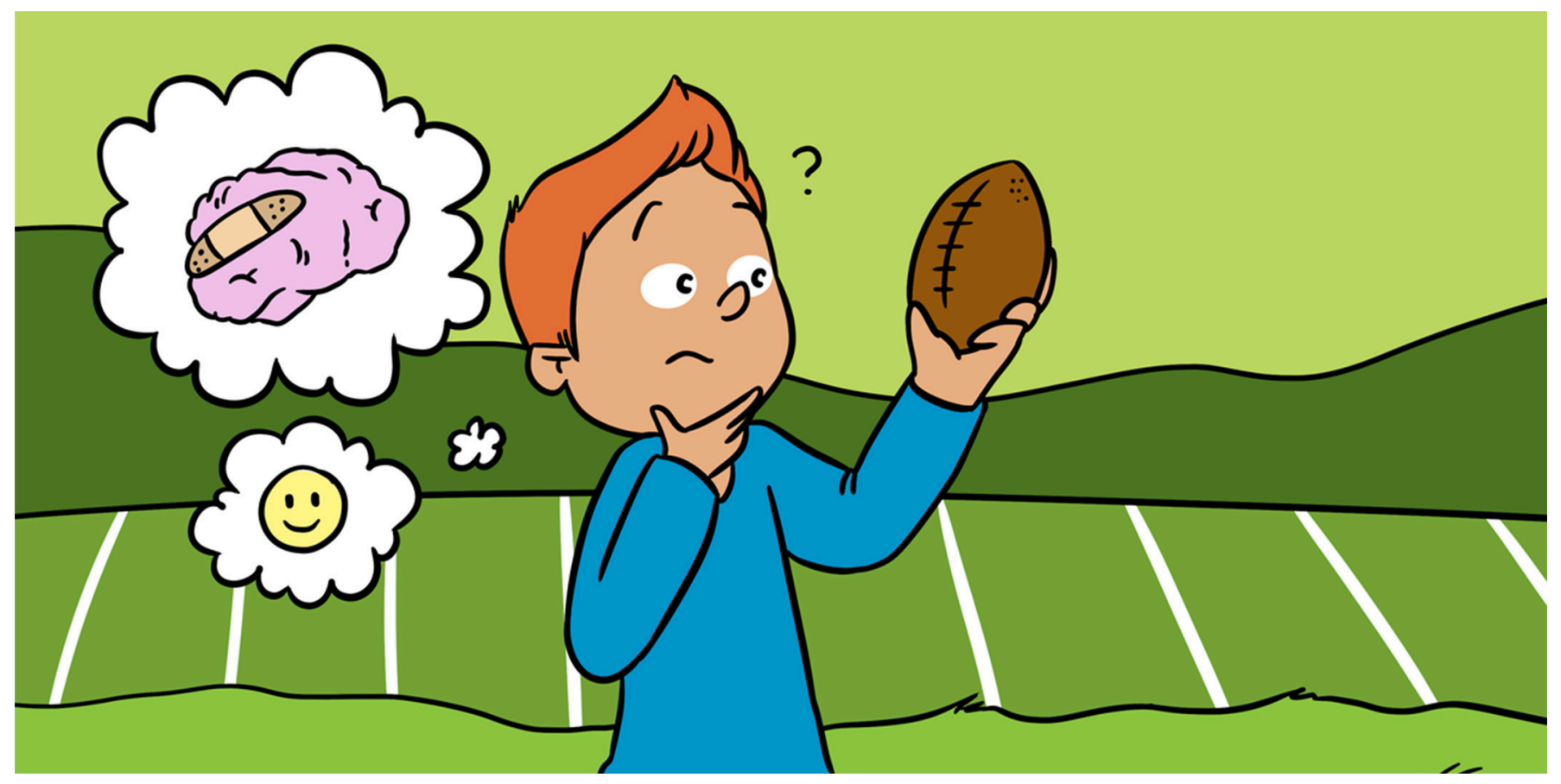

\title{
SPORTS ARE GOOD FOR YOUR MOOD, BUT A CONCUSSION IS NOT
}

\section{Amanda Clacy ${ }^{1 *}$, Daniel F. Hermens ${ }^{1}$, Kathryn M. Broadhouse ${ }^{1,2}$ and Jim Lagopoulos ${ }^{1}$}

${ }^{1}$ Sunshine Coast Mind and Neuroscience-Thompson Institute, University of the Sunshine Coast, Birtinya, QLD, Australia

2Sydney Medical School, University of Sydney, Sydney, NSW, Australia

YOUNG REVIEWERS:

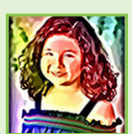

तु-
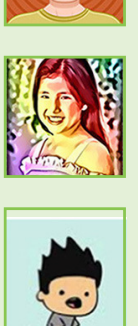

$\mathrm{NOAH}$

AGE: 14

VRISHAB

AGE: 9

WILL

AGE: 9
To play, or not to play, that is the question! We all know that sports are really good for your health. Did you know that playing in a team sport during adolescence has been shown to improve brain development and can protect you from developing a mood disorder? On the flip side, playing a sport can also place you at risk of getting an injury, like a concussion. Concussion is an injury to the brain that happens quite often when people play sports like football, netball, and soccer. The damage a concussion can do to someone's brain might increase their risk of developing a mood disorder later in life. In this article, we are going to discuss the benefits that participation in team sports can offer to healthy brain development and mental health, as well as the potential damage sports-related concussion can do to brain function and mood.

There are heaps of different things that can support healthy brain development during adolescence (ages 12-18), but there are also some things that might not be so good for our brains. In this paper, we 


\section{ADOLESCENCE}

The stage of development between childhood and young adulthood, typically between 12 and 18 years of age.

\section{MOOD DISORDERS}

A psychological disorder in which a person's feelings and emotions remain either too active (such as anxiety) or not active enough (such as depression) over several weeks.

\section{CONCUSSION}

An injury to the brain that occurs when someone is hit in the head or body, causing the brain to be thrust forwards or backwards in the skull, which disrupts normal brain function. will talk about why sports are good for the brain during adolescence, because they not only offer some protection against the development of mood disorders but can also help people who have mood disorders to feel better. But we will also talk about how getting a concussion while playing a sport might put someone at risk of developing a mood disorder later in life.

In this article we are going to talk about things like depression (feeling sad or empty), anxiety (feeling worried or stressed a lot of the time), and suicidality (not wanting to live anymore). If you are struggling with any feelings like this, or are worried about your mental health at all, please talk to a trusted adult, such as a parent, a teacher or counselor, or your doctor.

\section{MOOD DISORDERS IN ADOLESCENTS}

Mood disorders, such as depression and anxiety, are big mental health problems for young people all over the world. Having a mood disorder can make it difficult for a young person to develop positive relationships with friends and family, concentrate at school, or feel hopeful about the future. When someone feels these kinds of things over weeks or even months, that person may begin to experience depression (feeling really low and empty) or have thoughts of suicide (not wanting to live any more). Mood disorders, such as depression and anxiety play a part in the development of suicidal thoughts and behaviors (also called suicidality). It is really important that we look for ways to prevent the development of mood disorders and also ways to help young people who have mood disorders to feel better.

The brain goes through a lot of changes during adolescence. In regard to mental health in young people, these changes can make the brain quite sensitive to injuries. Let us start by talking about how the various areas of the brain are connected to each other. Regions of the brain need to communicate with each other so that we can think, plan, and carry out tasks in everyday life. The brain is made up of gray matter and white matter. Gray matter contains the cell bodies of neurons (which are the building blocks of the brain that process information). White matter consists of parts of neurons called axons, which are the connections that link different regions of gray matter together (see Figure 1). During adolescence, the white matter begins to decide which brain areas need to be connected the most. Think of this like a road map. Big cities get visited by more people more often, so highways are built to make sure that people can access these places quickly and easily. On the other hand, little country towns might only have dirt tracks connecting them, because they do not get visited as often. In the same way, as the brain develops throughout adolescence, it prioritizes building the white matter connections that we use the most and removes those that we do not use anymore (see Figure 2; 
Figure 1

Our brains are made up of billions of neurons. Gray matter is made up of the cell bodies of neurons, and white matter is made up of the myelin-covered connections (known as axons) that link different regions of gray matter together.

\section{Figure 2}

The white matter "road map" of our brains is shaped throughout adolescence to strengthen the highway connections between the regions of the brain we use most often and delete the dirt track connections we do not use. At the same time, our gray matter becomes more dense in the regions of the brain we use most. Think of it like little cities in the brain, where gray matter sky-scrapers and shopping centers are built so lots of business and activity can happen in one spot. By the end of adolescence, a healthy brain will have a well-formed network of white matter highways and dense gray matter cities, to help us process lots of information quickly and effectively.

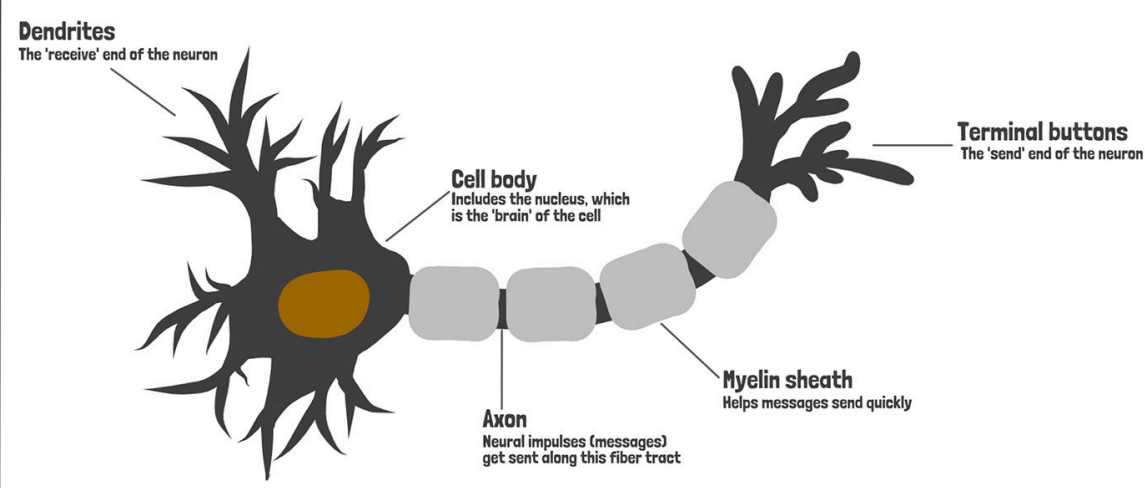

Figure 1

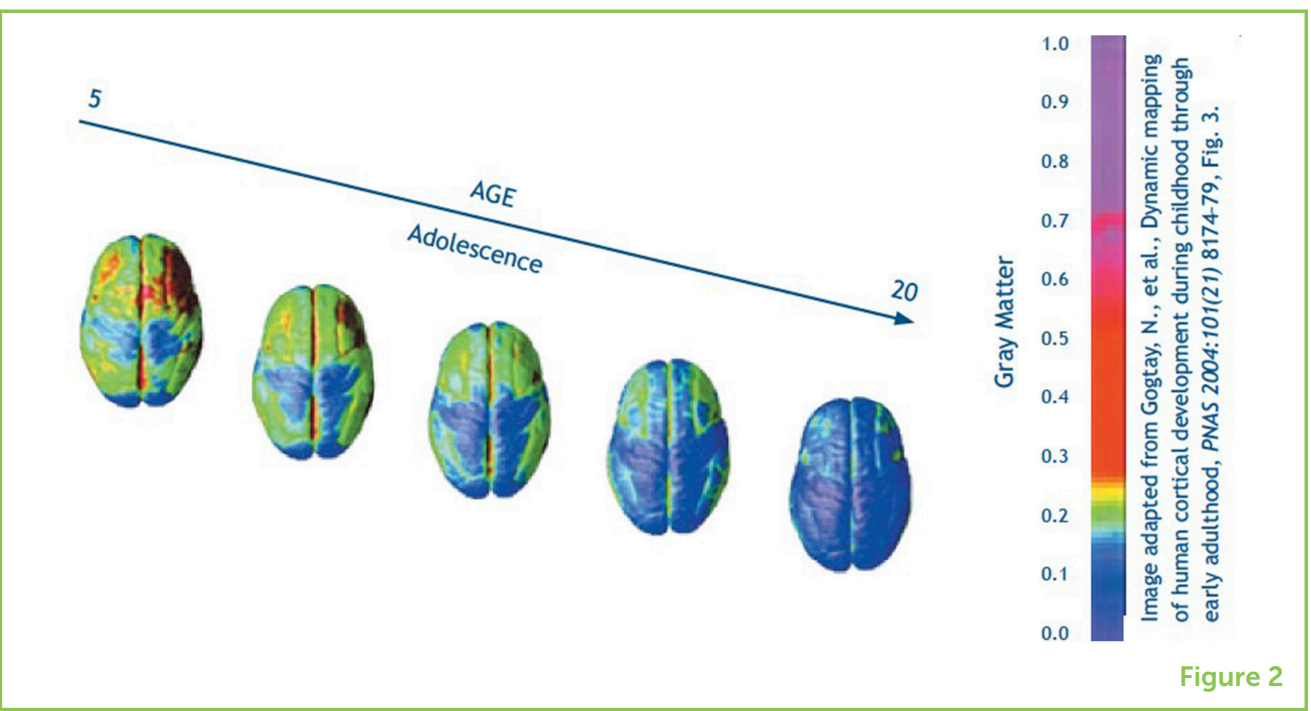

[1]). This allows the brain to quickly respond to certain, common things without you having to think about them too much.

During adolescence, the prefrontal cortex (PFC) and the limbic system are two regions of the brain that are under major construction (see Figure 3). The PFC is involved in making decisions and in goal-directed behavior (thinking about what you want to do, how to do it, and then doing it). The limbic system controls our feelings, memories, and stimulation (which allows us to explore, learn, and discover interesting things). Research has found that young people who experience mental health issues like suicidality, anxiety, and depression during adolescence are at risk of their white matter highways failing to connect these important regions of the brain properly [2]. If the connections between the PFC and the limbic system are not healthy and strong, it is more difficult for someone to solve problems, set goals, and manage emotions in a healthy way. When they cannot do these important tasks, people can begin to feel sad, stressed, and overwhelmed. Unfortunately, these kinds of difficulties place young people at risk of developing a mental illness. 
Figure 3

During adolescence, the prefrontal cortex (PFC) and limbic system are two regions of the brain that are under major construction; they are connected by the anterior cingulate cortex (ACC). The PFC helps us to make decisions and process information, and the limbic system helps us to process our emotions.

\section{NEUROGENESIS}

The growth of neurons. The opposite of this is neurodegeneration, which is the death of neurons.

\section{BRAIN PLASTICITY}

Our brain's ability to change and adapt to new and different things.

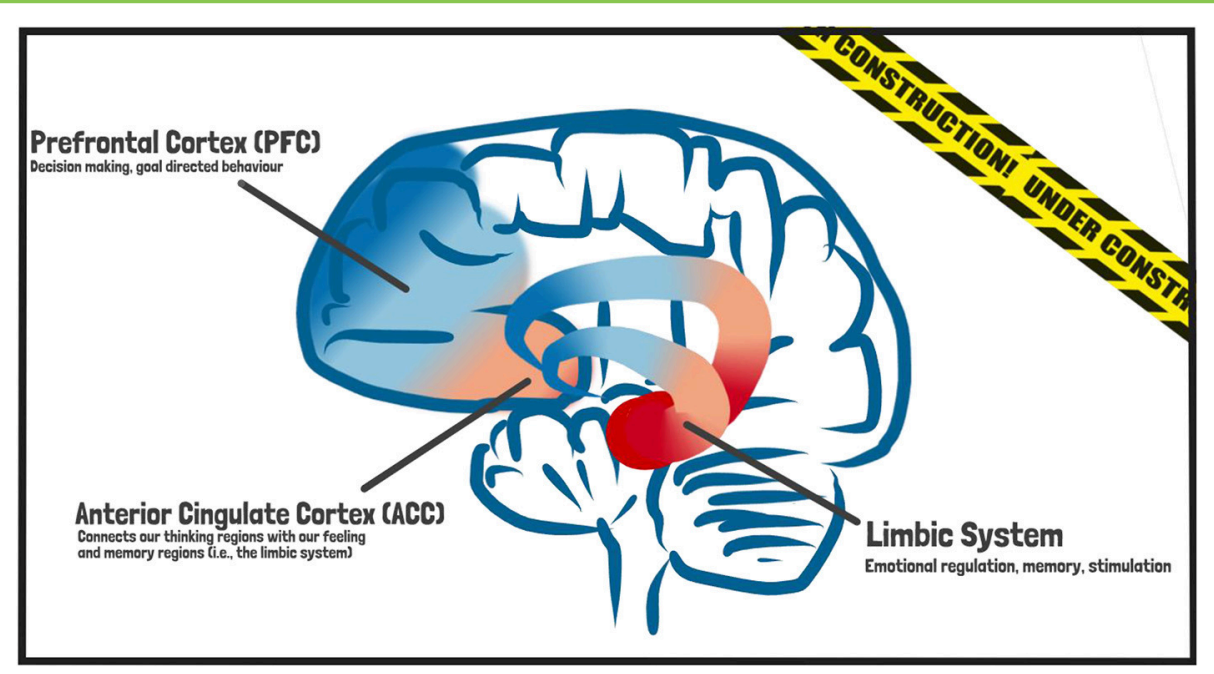

Figure 3

\section{SPORTS ARE GOOD FOR THE DEVELOPING BRAIN}

There are lots of different ways we can help support healthy brain development throughout adolescence. One of these is physical activity. Through its effect on how we think and feel, as well as its effect on the way our brains form, physical activity has been shown to significantly benefit adolescent mental health and development. How does this happen? Research has shown that physical activity improves brain development during adolescence through its positive effect on neurogenesis (the growth of neurons) and brain plasticity (the ability for the brain to change and adapt to new and different things) [3]. Playing a team sport can offer even more protection and developmental perks than just physical activity alone! Participating in a team sport exposes a person to both the benefits of physical activity on the brain, as well as to great social support and engagement with other people.

By participating in team sports, adolescents are more protected against mood disorders, because they feel more involved with their friends, they feel better about themselves and their skills, and they feel more confident in social settings [4]. This is exactly what we want to see, because young people who have strong relationships with their friends and family have been shown to be more resilient, hopeful, and positive about their lives, which is basically the opposite of having depression or thoughts of suicide. These effects of team sports can help the brain make strong, positive connections and provide lasting benefits to a young person's mental health.

\section{CONCUSSION AND MOOD}

Unfortunately, because many team sports involve a lot of people moving quickly, there is a risk that players might get injured. 
Concussion is an injury to the brain that occurs when someone is hit in the head or body, causing the brain to be thrust forwards or backwards in the skull, which disrupts normal brain function. Concussions can feel and look different in different people. Some people with concussions might become forgetful, others might become grumpy or depressed; others might get a really bad headache or feel like they are going to be sick. Some people might even experience a combination of these different symptoms. Young athletes might feel these symptoms straight away or it might take hours or even days for the symptoms to emerge. If you think you have a concussion, you should visit your doctor to get checked out, just to be on the safe side. Most people will recover from a concussion in about 2 weeks without any ongoing symptoms or major disruptions to their brain development. However, there are some people who, following a concussion, continue to have problems with things like memory and emotions. This may be because of injury to the parts of the brain that control these functions.

The brain regions that have been shown to be most impacted by concussions include the PFC and the limbic regions of the brain. These are the same regions of the brain that are under a lot of construction during adolescent development, and the same regions that are involved in mood disorders like depression and suicidality. This might be why concussions and depression share so many symptoms (see Figure 4). The damage a concussion can do might actually place a young person at risk of developing a mood disorder later in life, because it impacts the same brain regions that are rewiring and developing during adolescence. In fact, adolescents with a history of concussion have been found to be over 3 times more likely to experience depression in their lifetime, compared with young people who have never had a concussion [5]. Research looking at depression and suicide in adult and retired athletes has begun to show us that concussion may undo a lot of the good things that sports do for the brain. For example, concussions have been linked with neurodegeneration (the early death of neurons), reduced brain plasticity, and the development of depression and suicidality [6]. Unfortunately, we do not yet know what the long-term emotional and developmental consequences are for young people who get a concussion.

\section{TO PLAY, OR NOT TO PLAY?}

A lot of research still needs to be done to improve our understanding of the interactions between participation in team sports, concussion risk, and long-term mental health outcomes for adolescents. Most of the research we have on concussions and how they relate to the development of depression and other mood disorders has not been looked at in adolescents. This makes it difficult to totally understand the long-term impact of concussions on youth mental health. As we have said, adolescence is a sensitive time in the development of the 
Figure 4

These are some of the symptoms shared between concussion and depression. These similarities might occur because the PFC and the limbic system are shown to be affected in both conditions.

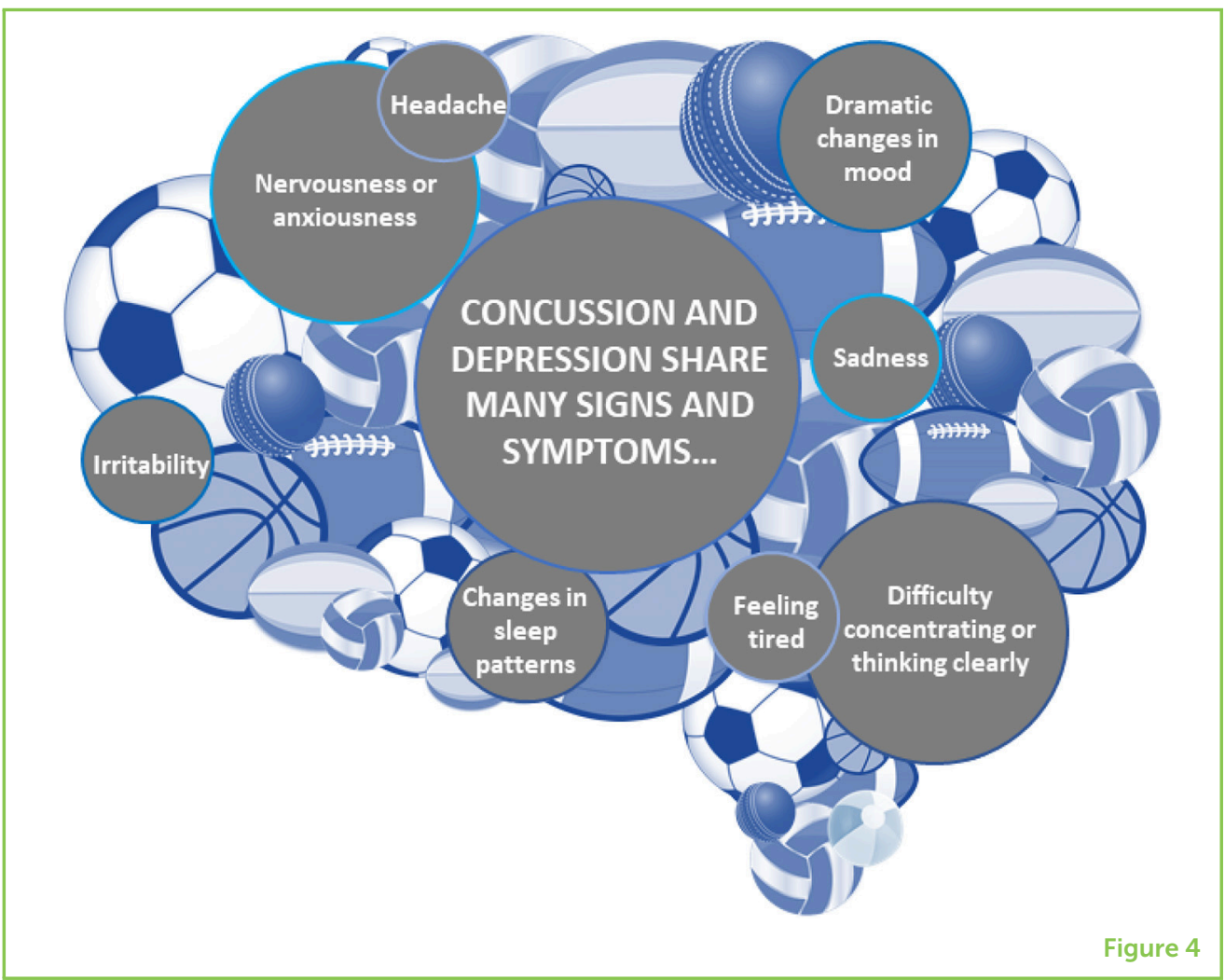

brain. We need to make sure we are doing everything we can to support happy, healthy development throughout this period, which includes being physically active with friends!

Remember, if you are struggling with feelings of sadness, anxiety, or stress, or if you are worried about your mental health at all, please talk to an adult that you trust.

\section{REFERENCES}

1. Gogtay, N., Giedd, J. N., Lusk, L., Hayashi, K. M., Greenstein, D., Vaituzis, A. C., et al. 2004. Dynamic mapping of human cortical development during childhood through early adulthood. Proc. Natl. Acad. Sci. U.S.A. 101:8174-9. doi: 10.1073/pnas.0402680101

2. Cao, J., Chen, J. M., Kuang, L., Ai, M., Fang, W. D., Gan, Y., et al. 2015. Abnormal regional homogeneity in young adult suicide attempters with no diagnosable psychiatric disorder: a resting state functional magnetic imaging study. Psychiatry Res. 231:95-102. doi: 10.1016/j.pscychresns.2014.10.011

3. Saraulli, D., Costanzi, M., Mastrorilli, V., and Farioli-Vecchioli, S. 2017. The long run: neuroprotective effects of physical exercise on adult neurogenesis from youth to old age. Curr. Neuropharmacol. 15:519-33. doi: 10.2174/1570159×14666160412150223

4. Eime, R. M., Young, J. A., Harvey, J. T., Charity, M. J., and Payne, W. R. 2013. A systematic review of the psychological and social benefits of participation in sport for children and adolescents: informing development of a conceptual 
model of health through sport. Int. J. Behav. Nutr. Phys. Act. 10:98. doi: 10.1186/1479-5868-10-98

5. Chrisman, S. P., and Richardson, L. P. 2014. Prevalence of diagnosed depression in adolescents with history of concussion. J. Adolesc. Health. 54:582-6. doi: 10.1016/j.jadohealth.2013.10.006

6. Fralick, M., Sy, E., Hassan, A., Burke, M. J., Mostofsky, E., and Karsies, T. 2018. Association of concussion with the risk of suicide: a systematic review and meta-analysis. JAMA Neurol. 76:144-151. doi: 10.1001/jamaneurol.2018.3487

SUBMITTED: 10 December 2018; ACCEPTED: 25 March 2019; PUBLISHED ONLINE: 12 April 2019.

EDITED BY: Amy J. Markowitz, University of California, San Francisco, United States

CITATION: Clacy A, Hermens DF, Broadhouse KM and Lagopoulos J (2019) Sports Are Good for Your Mood, Buta Concussion Is Not. Front. Young Minds 7:55. doi: 10.3389/frym.2019.00055

CONFLICT OF INTEREST STATEMENT: The authors declare that the research was conducted in the absence of any commercial or financial relationships that could be construed as a potential conflict of interest.

COPYRIGHT @ 2019 Clacy, Hermens, Broadhouse and Lagopoulos. This is an open-access article distributed under the terms of the Creative Commons Attribution License (CC BY). The use, distribution or reproduction in other forums is permitted, provided the original author(s) and the copyright owner(s) are credited and that the original publication in this journal is cited, in accordance with accepted academic practice. No use, distribution or reproduction is permitted which does not comply with these terms.

\section{YOUNG REVIEWERS}

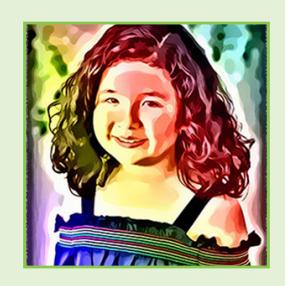

\section{CHARLOTTE, AGE: 9}

Charlotte is in fourth grade and loves playing soccer, mastering new math concepts, and reading books about adventurous kids. She sleeps on the top bunk and her favorite snack is pita chips. Charlotte barely tolerates her twin sister, but she adores her baby sister, who was born on Leap Day. Charlotte plans to study biology in college. She wants to attend a school where she can ride a Segway to visit her parents whenever she feels like it.

\section{DARREN, AGE: 9}

I like to do math, and reading in school. I am also very good at spelling. 

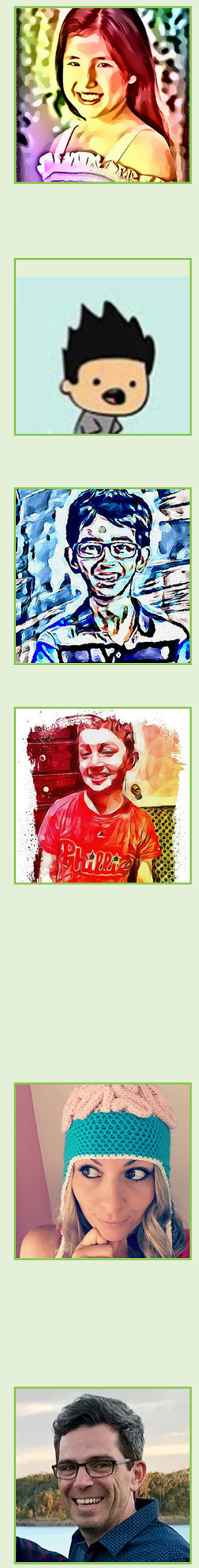

\section{JOSIE, AGE: 9}

Josie is in fourth grade and loves playing soccer, eating Korean food, and reading books about adventurous kids. She sleeps on the bottom bunk and her favorite junky snack is chips. Josie's best frenemy is her twin sister, but she absolutely adores her baby sister, who loves to wear overalls. Josie plans to study music in college and become a famous singer.

\section{NOAH, AGE: 14}

I am halfway through high school and my favorite subject is lunchtime, closely followed by Music and Science. When I grow up, I want to be an astrophysicist. I like to read in my free time. I do parkour, crossfit, and Air Force cadets outside of school, and I am writing a book about Australian SAS soldiers. I like to eat, especially enchiladas and bacon, but not at the same time.

\section{VRISHAB, AGE: 9}

I play the violin and flute. I like sports. I am very passionate about the environment and started a composting club at my school.

\section{WILL, AGE: 9}

I am a fourth grader in Philadelphia, PA. I love playing and watching sports, especially my hometown Philadelphia teams. I also like school, especially reading, writing, math and social studies. I have been playing drums for 3 years. I like going on trips like to the beach or to visit my grandparents in Florida. I also really like playing games with my little sister and building sports stadiums with blocks and magnet tiles.

\section{AUTHORS}

\section{AMANDA CLACY}

In my research on head injuries and mood disorders, I use both neuroscience and community research methods to make sure that I am getting the facts about things that matter most to everyday people. My favorite part of my job is talking to people in the community about what is important to them. My goal as a researcher is to help create a world that brings out the best in people. In my spare time, I like climbing mountains, taking my dogs kayaking, and crocheting brains and fun critters. *aclacy@usc.edu.au

\section{DANIEL F. HERMENS}

I am a brain scientist and I study mental disorders, including ADHD, depression and psychosis. My research has focused on adolescents and young adults, which I think is the most interesting and dynamic time of life in terms of brain changes. Currently, my favorite part of the brain is the hippocampus. When I am not doing research, I like to gaze at architecture, go on long bike rides or dance "robot-style" with my two daughters while we listen to Daft Punk. 


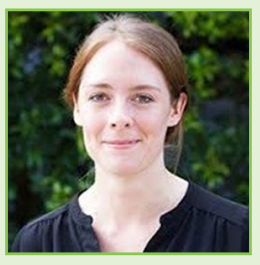

\section{KATHRYN M. BROADHOUSE}

I decided I wanted to study science and more specifically Physics at high school as I loved to learn how things and the universe work. When deciding my career, it was really important for me to be doing what I love, but also feel my work was meaningful and helping society. I therefore decided to specialize in medical imaging as this field combines a lot of the fundamental principles of physics to investigate and understand disorders and disease.

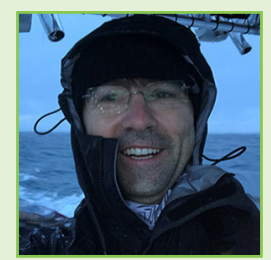

\section{JIM LAGOPOULOS}

In my career as a brain scientist I have taken over a million pictures of brains and studied many different areas of mental health. One of my favorite parts of my job is sharing my passion for brain research with up-and-coming scientists. I believe the more we know about the brain, the more we can help people to live their best lives. When I am not researching brains, I like to go on adventures. Some of my favorite adventures are deep sea fishing, climbing big mountains, and being with my kids. 